\title{
Vozes de crianças e adolescentes: o que dizem da escola?
}

\author{
Luciana Gageiro Coutinho1, https://orcid.org/0000-0001-5535-5931
}

Cristiana Carneiro², https://orcid.org/0000-0002-4042-1155

Larissa Magalhães Salgueiro', https://orcid.org/0000-0002-4153-2527

\begin{abstract}
Resumo
O artigo aborda a importância das pesquisas com crianças e adolescentes, nas quais se preconiza o olhar para esses como sujeitos, e não como seres em formação, apresentando uma análise de parte do material de uma pesquisa-intervenção realizada em um setor de saúde mental infanto-juvenil que recebe um grande número de encaminhamentos vindos da escola. Parte da construção histórica dos conceitos de infância e escola, para compreender melhor o panorama atual em que se dá a relação entre ambos. Em seguida, pautando-se em pressupostos teóricos da psicanálise, apresenta algumas falas de crianças e de adolescentes recolhidas durante a pesquisa-intervenção, que expressam suas experiências na escola, levantando questionamentos sobre os ideais e as demandas sociais que norteiam o funcionamento escolar.
\end{abstract}

Palavras chave: Infância; adolescência; escola.

\section{Voices of children and adolescentes: what do they say of school?}

\begin{abstract}
The article addresses the importance of research with children and adolescents, in which it is recommended to look at these as subjects, rather than as beings in formation, presenting an analysis of part of the research-intervention material carried out in a child mental health sector who receives a large number of referrals from the school. Part of the historical construction of the concepts of childhood and school, to better understand the current panorama in which there is the relationship between both. Then, based on theoretical assumptions of psychoanalysis, it presents some statements of children and adolescents collected during the intervention research, who express their experiences in school, raising questions about the ideals and social demands that govern school functioning.
\end{abstract}

Key words: Childhood; adolescence; school.

\section{Voces de niños y adolescentes: ¿lo que dicen de la escuela?}

\section{Resumen}

En este artículo se aborda la importancia de las investigaciones con niños y adolescentes, en las cuales se preconiza la mirada para estos como sujetos, y no como seres en formación, presentando un análisis de parte del material de una investigación-intervención realizada en un sector de salud mental infanto-juvenil que recibe un gran número de encaminamientos que vienen de la escuela. Parte de la construcción histórica de los conceptos de infancia y escuela, para mejor comprender el panorama actual en que se da la relación entre ambos. En seguida, pautandose en presupuestos teóricos del psicoanálisis, presenta algunas hablas de niños y de adolescentes recogidas durante la investigación-intervención, que expresan sus experiencias en la escuela, alzando cuestionamientos sobre los ideales y las demandas sociales que apoyan el funcionamiento escolar.

Palabras clave: Infancia; adolescencia; escuela.

1 Universidade Federal Fluminense, Faculdade de Educação - Rio de Janeiro, RJ, Brasil.

2 Universidade Federal do Rio de Janeiro, Faculdade de Educação - Rio de Janeiro, RJ, Brasil. 


\section{Introdução}

Muito tem se falado sobre as questões e os entraves relacionados ao funcionamento escolar em vigor na realidade brasileira atual, gerando-se intensos debates e propostas para resolver tais questões. Porém, muitas vezes esses debates se realizam de forma adultocêntrica, ou seja, apenas entre os teóricos da área e/ou entre educadores, sem levar em conta os conhecimentos de quem está inserido nessa realidade, como por exemplo, os próprios alunos. Na contramão dessa tendência, este artigo aborda as especificidades da pesquisa com crianças e adolescentes, refletindo sobre a importância de se levar em conta o que dizem eles sobre a vida escolar para compreender e repensar a escola hoje.

Parece consenso entre os autores que se dedicam a pensar as especificidades da pesquisa com esse público a visão de que as crianças e os adolescentes são sujeitos, capazes de falar e expor sua posição no mundo, contrapondo-se à visão mais tradicional da psicologia do desenvolvimento que os tomava como "seres em desenvolvimento", o que justificou muitas vezes observação do olhar do pesquisador adulto (Castro 2008; Rhoden, 2012; Souza, 1996), A partir de uma crítica a essa visão do desenvolvimento psicológico, é possível pensar outras abordagens da infância e da adolescência, em que ao colocarem a centralidade da linguagem na subjetivação, nos levam a entender a importância de ouvir as crianças, pois elas são plenamente capazes de falar por si próprias sobre suas experiências e contar como elas compreendem a escola de que fazem parte. Segundo Rhoden (2012) ao inserir crianças em pesquisas, estamos admitindo que elas são sujeitos plenos de conhecimento e autenticidade, pois, ao retratar aspectos sobre a sua realidade, elas são fiéis com relação às suas interpretações e credos.

Assim, em vez de falar da criança, sobre ela, ou por ela, ela própria passa a ter voz ativa. Essa postura proporciona um grande salto no âmbito da pesquisa, pois trabalha-se com a participação das crianças e adolescentes nas temáticas que lhes dizem respeito, mas que são pertinentes também ao universo social mais amplo. Escutar as crianças e os adolescentes pode ter uma potência transformadora, o que leva a aceitar o desafio de que é preciso ouvi-las no que tem para dizer e tornar as suas falas como centrais no entendimento das circunstâncias em que estão inseridas. Nesse sentido, nossa aposta é que, ao darmos voz às crianças e os adolescentes, podemos obter um novo e inovador olhar sobre a escola.

\section{O lugar da escola no ideário moderno: assepsia ou desejo?}

É preciso evocar a história, voltar ao surgimento dos significantes "escola" e "criança" para que possamos analisar as vozes das crianças e adolescentes descrevendo a escola atual. Tais significantes que existem hoje nem sempre existiram, eles surgiram em um momento histórico específico, e em um contexto social específico. Em História Social da Criança e da Família, Ariès (1981) mostra que durante a Idade Média, a criança era tomada como um adulto em miniatura, ou seja, assim que conseguia realizar tarefas básicas sem ajuda, era integrada ao mundo dos adultos. Não se tinha uma vestimenta ou hábitos/atividades sociais individuais para essa "fase" da vida, e a educação ocorria por convivência com os mais velhos, que lhe passavam uma função.

Foi apenas entre os séculos XVI e XVII que este panorama começou a se modificar. Tinha-se então, um novo sentimento de infância, além de se ter uma nova classe social que começou a emergir. Naquele contexto, formulou-se uma nova preocupação: as crianças precisavam se tornar pessoas honradas e homens racionais. Era preciso então "tratar de harmonizar a criança para preparar o adulto a fim de moldá-lo aos ideais da burguesia em ascensão" (Calastre, 1991, p. 137). A escola surge neste panorama histórico cultural. Ela entra como a instituição "responsável" pelo alcance de tal objetivo:

Como a escola e o colégio... se tornaram no início dos tempos modernos um meio de isolar cada vez mais a criança durante um período de formação tanto moral como intelectual, de adestrá-las, graças a uma disciplina mais autoritária, e, deste modo, separá-las da sociedade dos adultos (Ariès, 1981, p. 165).

Porém, a escola em seu princípio não era pensada para todos, incluía apenas os meninos pertencentes às classes mais abastadas (Ariès, 1981). Atualmente, temos um panorama diferenciado, a escola passou a ser uma obrigação referendada pela legislação, não é uma opção. Assim, temos uma posição quase que naturalizada, de que lugar de criança é na escola (Souza, 1996).

É notório que passamos a compreender essa educação dada às crianças dentro do ambiente escolar como de extrema importância para o andamento e desenvolvimento de nossa sociedade, porém a obrigatoriedade escolar não assegura que sua função consiga ser realizada. Logo, o adulto acaba sendo instigado a pensar sobre como a criança se sente em relação a esta "obrigação escolar". Uma pesquisa realizada no Rio de Janeiro com crianças de 7 a 12 anos, provenientes de diferentes camadas sociais, frequentando escolas públicas e privadas, (Souza, 1996) mostra que muitas vezes a escola quando associada ao estudo ocupa um lugar de desprazer, e quando associada ao espaço de fazer amigos, brincar ou subverter a ordem estabelecida, é compreendida como fazendo mais sentido. Parte-se então para uma constante busca para que o lúdico e a obrigação tornem-se experiências compatíveis, para assim tentar fazer com que a experiência escolar tenha sentido para as crianças/adolescentes.

A criação da escola como um ambiente supostamente separado do mundo, onde pudéssemos prevenir a "entrada" da corrupção do mundo adulto, coaduna-se à ideia de assepsia no seu sentido de prevenção da entrada do patológico, do germe no organismo. Neste ideário a criança "pura" deveria ser preservada à distância. Esta lógica reforçou a crença num ambiente escolar integralmente pleno e moral, separando todo o "resto" que é considerado inapro- 
priado. Entretanto, ainda que se tente afastar esse "resto", ele insiste em emergir, já que é impossível descartá-lo de uma vez por todas. Aopção que muitas vezes se encontra, é problematizá-lo de forma individual, como sendo algo exclusivo daquele aluno, daquela instituição ou daquele professor, e assim aumenta-se a demanda por especializações que irão tratar o cerne da questão de uma mesma forma: individualizar e corrigir.

Trazendo à tona a questão do desejo, a psicanálise pode nos oferecer uma outra abordagem da escola e do processo educativo. Para Calastre (1991) Lacan situa a ocorrência do "evento Freud", quando põe em xeque essa criança educada, policiada e disciplinada.

A nova criança que Freud mostra é antes de tudo um corpo, mas um corpo que não consegue fazer a aprendizagem da satisfação, que não consegue regrar seu prazer segundo as vias previstas pelo Outro (sempre é muito pouco, ou demais, ou não é assim), em suma, é um corpo ineducável, que faz fracassar todas as idéias recebidas sobre uma progressão harmoniosa. Freud anuncia tranquilamente que a criança goza, e de maneira perversamente polimorfa: não agrada aos pais de família (Calastre, 1991, p.138).

Assim, quando se fala de crianças e adolescentes, não se pode pensar em algo genérico, partindo do (pre)conceito sobre o que seria uma criança/ adolescente. Fala-se então do sujeito, que, partindo dos princípios da psicanálise, é um sujeito do inconsciente. Logo, existe uma divisão e um conflito. E esse conflito é constituinte do sujeito e irredutível ao longo da vida. Vemos em Freud (1923/1980a), que liberdade não é um sujeito sem conflitos, pois o real jamais seria abarcado totalmente pelo psiquismo. Liberdade seria a possibilidade de transformação do sujeito, ou seja, quando o sujeito se apropria de algo, que a princípio é sentido como uma imposição imutável vindo de fora - contudo estranhamente familiar- e a torna mutável, modifica seu sentido, dando um sentido próprio e familiar.Porém essa familiarização não é definitiva e nem completa, assim, pode-se afirmar "é sob a visão de um conflito permanente que se assenta a ideia de um inacabamento para o sujeito, de um sujeito que será sempre dividido, consciente e inconsciente, e terá que se haver com um real que insistentemente interpela o psíquico." (Carneiro \& Coutinho, 2014, p. 36). Têm-se então, um conflito, que quando trabalhado, torna-se motor, ou seja, abre espaço para que se consiga realizar novas produções.

A escola, desde a sua consolidação até os dias de hoje, muitas vezes vem sendo vista como um local onde se atingirá uma plenitude, tanto em seu funcionamento, quanto em suas normas ou no que se diz respeito ao aprendizado do aluno, porém isso é uma visão idealizada. Os saberes e o mal-estar que os próprios alunos sentem em seu dia-a-dia na escola (afinal é lá que eles passam a maior parte dos seus dias) muitas vezes não são considerados ou então, são percebidos, porém ignorados, fechando qualquer possibilidade para que o aluno possa utilizá-los de uma forma mais produtiva porque é transformadora. Isso ocorre por inúmeros motivos; por pensar que a escola não é lugar para tal, ou até mesmo pelo fato de o professor não saber o que fazer com isso que chega até ele. Porém, idealizar a escola como um lugar "asséptico" para melhor funcionar é algo puramente ilusório. Primeiro porque as crianças percebem o "saber fracassado" do adulto, ou seja, "nós falamos para as nossas crianças a partir de uma posição de ideal. E nossas crianças sabem perfeitamente que em relação a esse ideal nós mesmos estamos em dificuldades; quer dizer que nós mesmos estamos constantemente atrapalhados pelo nosso ideal" (Melman, 1994, p. 33).

Em segundo, porque, para que um indivíduo surja como sujeito, é preciso que haja um investimento pulsional e dos sentidos, que começa antes mesmo do seu nascimento, ou seja, o sujeito nasce em resposta a isso que lhe antecede. Quando se pensa na transmissão em educação, não há como pensá-la afastada da ideia do surgimento do sujeito, ambas ocorrem de forma similar, como já dizia Kupfer (1995) a psicanálise aposta que a transmissão e a apropriação de um saber são sempre marcadas pela presença de um sujeito desejante, tanto daquele que transmite, quanto daquele que recebe e transforma o que recebeu. Logo, é preciso sair do lugar de objeto para que o sujeito se constitua.

Além disso, para que se tenha a possibilidade de o sujeito emergir, é necessário que não se tenha um saber pleno, pois quando este existe, se objetaliza a criança. Isto quer dizer que quando se acredita em um saber pleno, espera-se que alguém (que retém o saber) fale por você, deixa-se então, de se ter um enigma, não existe pergunta, pois é o outro que sabe. Vemos que isso ocorre muito com as crianças, um outro que fala e sabe por ela. Isso ocorre, pois muitas vezes a infância é vista como um período em que a criança é um ser incompleto, inacabado e em desordem, e que, comparada ao adulto, fica depreciada. Assim, tem-se uma anulação da voz da criança e prevalece a observação do adulto para com a criança. Logo, a escola asséptica correm grande risco de ficar nesse lugar de anular a voz da criança/adolescente, já que acredita numa criança universal que "ainda não é”, partindo do princípio que existiria uma escola também universalizante. Nessa ótica, acredita-se também numa educação homogênea, que acaba por excluir a singularidade e a construção de um espaço que considere o saber da criança.

Em seu texto Hiperatividade, comportamento opositor e déficit de atenção, por exemplo, Cristina Merletti (2012) põe em questão algo que nos leva a pensar sobre um mal-estar social do adulto em relação, não somente às crianças supostamente com problemas, mas em relação ao lugar do infantil na contemporaneidade. Ela ressalta que

O discurso científico tende a construir seus objetos de saber e, no que se refere ao saber sobre a infância, tende a produzir um saber sobre A Criança, desconsiderando o que representaria uma criança para cada pai e para cada mãe. Nesse sentido, supomos que o discurso científico sobre a infância tende a tomar a criança como um objeto, descritível, previsível e controlável, desconsiderando justamente o que a tornaria singular - sua subjetividade e sua história tecida 
na relação com seus pais. Referimonos aqui a um fenômeno que denominamos de objetalização da criança no discurso tecno-científico. (Merletti, 2012: p.3).

Nesse sentido, é fácil perceber que, diante de demandas tão incisivas de muitos pais a respeito de seus filhos ou de escolas a respeito dos seus alunos - sobre como controlá-los ou adequá-los em variadas situações -, a maioria dos profissionais sente-se tentada a responder prontamente, orientando-os por meio de informações, técnicas ou métodos e tamponando uma falta fundamental na direção da promoção da construção dos saberes próprios sobre a infância. Nesse panorama de individualização e do surgimento da expressão "criança-problema", podemos nos perguntar se alguém pode aprender quando é considerado incapaz de fazê-lo.

Durante o início do século $\mathrm{XXI}$, além dos rótulos dados ao "aluno-problema" - marcando-o como aquele que não consegue aprender - uma série de classificações patológicas começam a surgir para explicar as dificuldades na escola. A medicalização surge e se insere rápida e intensa no contexto escolar, passando a caracterizar o sujeito como se ele fosse uma simples soma de características biológicas e comportamentais (Christofari, Freitas, \& Baptista, 2015).

Como argumentam muitos teóricos da Educação (Saviani, 2005; Lukesi, 2003; Vasconcellos, 1992), a escola hoje vive sob uma forte tendência neoliberal aliada ao discurso da técnica, caracterizada pelo individualismo e pela extrema competitividade fundamentada pela ideologia meritocrática que exige dos educadores uma educação voltada para o mercado. Ainda que no campo educacional, muitas vezes, haja rejeição a essa postura mercadológica, no cotidiano da escola verifica-se que há um tensionamento bastante presente entre a formação humanista dos educadores e as exigências instrumentais que a prática traz para eles.

Voltando à escola ideal e à busca por um saber que prima pela eficácia na educação é perceptível também notar que isso se coaduna com a presença atual de um ideal de felicidade plena na sociedade ocidental. Como nos mostra, Audino (2015) na era da globalização, em que as possibilidades tecnológicas são imensas, verificamos que essas mudanças, não somente provocaram o triunfo e o estabelecimento de uma sociedade de consumo, como também contribuíram para novos ideais de felicidade. Esse processo tem início com a Revolução Industrial e o subsequente desenvolvimento tecnológico a que ela nos levou, seja com os avanços nas telecomunicações e a expansão das fronteiras geográficas, seja com a enorme expansão da indústria farmacêutica (com o surgimento de contraceptivos orais, antidepressivos, ansiolíticos, viagra, etc.) Isso tudo contribui para a instauração do imperativo da felicidade e o apelo ao prazer imediato na sociedade contemporânea.

De modo avesso ao que preconiza Freud, hoje vige a busca por uma felicidade idealizada e inalcançável, ou seja, busca-se a liberdade individual ilimitada, principalmente a liberdade de buscar o prazer. A psicanálise nos ensina que abusca por uma felicidade que irá permanecer para sempre, de forma sempre estável, aponta para um impossível.
No texto "O mal-estar na civilização" Freud nos fala de três fontes de desprazer, que são inevitáveis e intrínsecas à vida humana: a adversidade da natureza, nosso corpo e as relações interpessoais. Logo, a felicidade plena, onde não se tem sofrimento e inquietude é algo inatingível que, no entanto, homem está sempre tentando buscar. Entretanto, segundo Freud, isso não é algo necessariamente ruim, já que " a inquietude que isso (as três fontes de desprazer) provoca proporciona à raça humana um movimento em busca de melhoria individual e coletiva" (Freud, 1930/1980b, p 50). Além disso, diz ele que é justamente por conhecermos o desprazer que reconhecemos a felicidade: "somos feitos de modo a só podermos derivar prazer imenso de um contraste, e muito pouco de um determinado estado de coisas que perdure" (Freud, 1930/1980b, p 50).

Outro ponto interessante levantado por Melman (1994, p. 32) é a ideia de que "cada um de nós, em relação à educação que recebeu, tem uma relação ambígua, pois em geral nós a amamos, visto que lhe devemos tudo, ao mesmo tempo a detestamos, pois é evidente que ela fracassou conosco". Assim, ao trazer a dimensão do "fracasso", o autor marca que a educação nunca conseguirá atender plenamente aquilo que se idealiza dela. Quando a máxima freudiana (1937/1980c) adverte sobre os três ofícios impossíveis: analisar, educar e governar; há uma impossibilidade apenas se idealizarmos o educar como algo que chega a uma finalização suficiente e definitiva. Ao se partir da ideia de que alguns desses ofícios podem ser racionalmente planejados e conduzidos por um saber ideal, que seria formulado e respaldado a partir do saber cientifico que pretende dar conta de toda a realidade, não há como nos depararmos com nada menos do que com a desilusão. Segundo Cifali (2009, p. 8) "O 'impossível' poderia ser aqui interpretado como o nosso pesar por não ter tais atos sempre garantidos cientificamente".

Assim, é possível reconhecer que a busca pela educação plena e pela felicidade "ideal" que chega à escola nos dias de hoje tem origem em um contexto social que dirige-se além de seus muros. Nessa ótica, a escola tem que ser muito "legal" e "colorida" em tempo integral. Entretanto, diante disso, não podemos deixar de nos indagar se, numa escola que prioriza o cognitivo ou que prioriza sempre uma pedagogia "animada", sobraria espaço para que a raiva, a tristeza e a decepção apareçam e sejam incluídas no seu dia a dia, e não postas de lado ou excluídas como patologias. Muitas vezes esses sentimentos são vistos como negativos, e por isso tenta-se a todo custo omiti-los, porém, questionamos aqui o quão alto pode se tornar para alguém essa omissão.

\section{Metodologia}

O presente trabalho discute alguns resultados parciais da pesquisa Infância, adolescência e mal-estar na escolarização: estudos de casos em psicanálise e educação, que se constituiu a partir de uma parceria entre o NIPIAC 
(Núcleo Interdisciplinar de Estudo e Pesquisa para a Infância e Adolescência Contemporâneas), as Faculdades de Educação da UFRJ (Universidade Federal do Rio de Janeiro) e da UFF (Universidade Federal Fluminense) e o Instituto de Psiquiatria da UFRJ, onde o trabalho se realizou, mais especificamente no SPIA (Serviço de Psiquiatria da Infância e Adolescência).

A pesquisa teve em seu primeiro momento, a realização de um estudo piloto, que aconteceu no primeiro semestre de 2012, e visou mapear a chegada dos usuários do serviço de saúde mental que tinham sido encaminhados pela escola. Ao se analisar as fichas de triagem, que além dos dados de identificação (nome, endereço, idade, responsáveis) contém, principalmente, o motivo da procura institucional, pôde-se constatar que as duas maiores queixas que ingressavam no setor eram: agitação e dificuldade de aprendizagem. Assim, tais queixas foram eleitas como categorias e se tornaram critérios de seleção dos casos a serem estudados.

Orientando-se por essas categorias, elegeram-se cinco casos que foram acompanhados por dois anos. Três crianças respectivamente de seis, sete e oito anos e dois adolescentes, uma de doze e outro de quinze. Duas crianças estudavam em escolas municipais, na Zona Sul do Rio de Janeiro, uma estudava numa ONG. Já em relação aos adolescentes, uma estudava em escola particular da baixada fluminense e o outro numa turma de PEJA do município do Rio de Janeiro. As famílias tinham baixo poder econômico, com exceção da adolescente cujos pais se descreviam como classe média. Visamos escutar cada um dos atores envolvidos na situação (pais, escola, médicos e criança/adolescente) a fim de observar de que forma o malestar aparece nesses diferentes discursos. A construção dos dados foi feita tendo como centro o discurso, que pôde ser obtido através do registro escrito e do registro falado. Também utilizamos a observação participante nas escolas, a fim de estudar a criança/adolescente no próprio contexto escolar. Quanto ao registro escrito, obtido através de análise documental, a principal fonte de dados foi o prontuário do caso que nos oferece relatório escrito dos médicos e especialistas, bem como relatórios escolares.

Foram feitas também reuniões mensais no SPIA/IPUB com as famílias em conjunto e entrevistas ou reuniões com os especialistas e com a escola. As reuniões de equipe multidisciplinar, compostas por professores e alunos das áreas da psicologia e da educação, além de psicólogos e psiquiatras do SPIA, foram entendidas como eixo importante para o estudo de casos já que os diferentes discursos podem, em um mesmo ambiente, circular de forma articulada bem como divergir em certos pontos. As entrevistas e reuniões foram gravadas e registradas em relatórios que servirão como material para análise.

A pesquisa-intervenção parte da premissa comum de que os sujeitos humanos se constituem no âmbito das práticas de significação, sempre numa situação partilhada com outros, sejam adultos, jovens ou crianças. Nesse sentido, a palavra ou qualquer ação do pesquisador vai se realizar na interlocução continuada com os sujeitos através da constru- ção de sentidos para as situações vividas. De acordo com Ferrari (2008, p. 88), a relevância da pesquisa intervenção estaria no fato de se ter um "operador que permite observar e definir diretamente um objeto e, simultaneamente, agir sobre ele e mudá-lo, gerando, assim, evidências externas sobre o social". Logo, o sujeito que se pretende investigar e conhecer é efetivamente constituído ao longo do processo de pesquisa por meio da interlocução com o pesquisador ou com outros que também se incluem na forma como essa experiência se produz.

A fim de se construir o dispositivo de pesquisa-intervenção pautado por um viés multidisciplinar, foram definidos quatro eixos de investigação para os casos: o sujeito (criança/adolescente); a família; especialistas e a escola. O material foi obtido e registrado durante os anos de 2013 e 2014, a partir de reuniões mensais com os pais (família); reuniões com os especialistas (psicólogos e psiquiatras, musicoterapeutas e fonoaudiólogos); reunião com os próprios sujeitos (crianças/adolescentes), ida à escola das crianças/ adolescentes e seus prontuários. As técnicas utilizadas para o registro foram as gravações realizadas de todas as reuniões e posteriormente suas transcrições, relatórios anuais de cada eixo e os prontuários.

No que diz respeito ao estudo de casos, Ventura (2007) aponta que o estudo de caso se tornou uma das principais modalidades de pesquisa qualitativa em ciências humanas e sociais, além das áreas médicas e psicológicas. $\mathrm{O}$ estudo de caso é uma investigação empírica que lida com condições contextuais que são pertinentes ao fenômeno do estudo. Além disso, compreende método abrangente que abarca o planejamento, as técnicas de coleta e a análise de dados. (Yin, 2005).

$\mathrm{Na}$ análise dos dados escolhemos trabalhar primeiro com o eixo sujeito - ou seja, com o discurso das próprias crianças e dos próprios adolescentes. Dentro desse eixo elegemos categorias e subcategorias de acordo com a convergência e divergência das falas dos sujeitos. Para tal, nos utilizamos dos relatórios elaborados a partir das transcrições das reuniões gravadas. Este artigo utilizou-se de uma categoria especifica na análise das falas das crianças e dos adolescentes: a descrição da escola. Tal proposta emergiu a partir da leitura das falas sobre como as crianças/adolescentes descreviam suas escolas. Por entendermos a criança e o adolescente como sujeitos, damos grande importância aos seus discursos, que acabam por nos mostrar muitas vezes uma escola diferente do olhar adultocêntrico muitas vezes predominante nos estudos sobre a infância e a adolescência (Castro, 2008).

\section{Resultados e discussão: vozes}

\section{das crianças e dos adolescentes}

Ao voltarmos nossa atenção para o lugar que a criança/adolescente ocupa dentro de uma pesquisa, é possível encontrar sua participação de diferentes formas. Algumas 
abordagens da psicologia do desenvolvimento, por exemplo, constroem uma relação com a infância que a aponta muitas vezes como um período no qual a criança é um ser incompleto, inacabado e em desordem (Souza, 1996). Nessa visão, quando associada ao adulto, ela fica depreciada, vista como objeto. Usando as experiências da criança, como os seus comportamentos cognitivos, afetivos, psicomotores, com o objetivo de explicar o processo do desenvolvimento humano, defendem que a evolução é progressiva e por etapas, além de fragmentar a criança/adolescente, em sua área cognitiva, social, motora, linguística, entre outras. Tais áreas são avaliadas como áreas ou setores de desenvolvimento, de acordo com a ênfase dada em cada teoria específica (Souza, 1999). Dentro dessa ótica, pesquisa-se uma criança parcializada, fragmentada e muitas vezes separada de seu contexto.

Acreditando em uma forma diferente de fazer pesquisa com crianças e adolescentes, ou seja, ao invés de ressaltar as informações coletadas e interpretá-las a partir do olhar adulto, acredita-se que crianças e adolescentes possuemuma voz relevante que deve se fazer valer. A partir do momento em que a criança/adolescente passa a ser tomada como sujeito, que possui toda capacidade de expressar aquilo que vivencia e a atinge, sua fala passa a ser de extrema importância, e aí surge a possibilidade de enxergar a riqueza de produzir uma pesquisa que se constitua "com" as crianças e não "sobre" as crianças. Assim, a criança/adolescente ocupa um novo lugar, passando a ter direito a voz e sendo incluída de forma ativa na produção de conhecimento sobre ela. É muito importante ressaltar que as falas não estão restritas apenas à palavra, pois a linguagem da criança é acompanhada de expressões corporais, gestuais e faciais (Rhoden, 2012)

Falar sobre como as crianças e os adolescentes descrevem a escola não é algo que pode ser feito de forma direta, pois existem muitos atravessamentos que participam dessa questão. Por exemplo, como a própria escola se descreve/ se enxerga? O que se espera da escola? Como a escola lida com o fato de que às vezes a descrição do aluno será muito diferente de como ela se enxerga e do que se espera de uma escola?

A partir das conversas com as crianças e adolescentes acompanhados pela pesquisa, pudemos constatar que, para além da idealização hegemônica sobre esta instituição chamada escola, que deveria atender a todos de forma plena, satisfatória e sem mal-estar, as experiências vivenciadas e descritas por eles acabam por desconstruir essa ideia. Em suas falas, de forma muito lúcida, as crianças e os adolescentes muitas vezes expressam que as exigências e os percalços da escola são inevitáveis. Podemos notar tal perspectiva, paradoxal e conflitante sobre a escola, de forma muito clara nas falas a seguir:

A professora de artes. O nome dela é Conceição. Ai a gente chama ela de Concentração. De vez em quando ela é enjoada, mas até que é legal.

Tem matéria que eu gosto e professor que é "macumbado", a maioria é de encher o saco do que os legais. Tem matéria preferida, tem! Tem gente que eu não gosto, tem! Tem inspetores que enchem o saco, tem! Tem diretora que é legal com você, tem! Tem a que enche o saco, tem! Tem, tem tudo. É praticamente um Zoológico, você acaba se surpreendendo com aquela escola. Sempre tem um tipo de animal novo, dentro da sala, fora da sala, sempre tem. A gente não fica no tédio.

Um Saco. Escola não é para ser legal, nenhuma escola é legal.

\section{(Menina de 12 anos)}

Nas duas falas acima a adolescente mostra que existe uma contradição natural dentro da escola: ao mesmo tempo em que ela é chata, também consegue ser legal. E essa contradição está instalada no contexto do que é viver em sociedade. Nem sempre a vida, assim como a escola, é tão divertida, porém essa "chatice" não é sem importância. Ela também faz parte da construção e elaboração do ambiente escolar.

Mas eu to falando! E eu também não gosto de lá porque lá é trancado (Menino de 16 anos)

Já na fala acima, é possível observar a percepção do adolescente de que a escola se isola do mundo ao seu redor, e isso aparece representado inclusive na sua estrutura física. Isso, às vezes aparece como um incômodo para os alunos, como se existisse uma separação sem sentido entre o fora e o dentro. No caso do adolescente acima, que morava numa comunidade e andava para cima e para baixo do morro várias vezes ao dia, o" trancado" parece indicar uma estranheza. Também aparece nas falas um desgosto quanto ao estudar.

Entrevistadora: Você se acha um bom aluno? É legal ir pra escola?

G.S.: Mais ou menos... Porque eu não gosto de estudar

(Menino de 10 anos)

Entrevistadora: Te deu muito trabalho fazer essa conta, né? $E$ me conta uma coisa, o que você acha mais maneiro na escola?

E: Bom na hora de brincar... tem muita brincadeira, ai, ai a gente inventa nova, tipo a corda de pular a gente vai, a gente inventou rasteira. A pessoa pega a corda e fica rodando assim... Ai fez é, também a brincadeira de chutar, caramba eu, três no meu time inimigo e só eu no meu.

(Menino de 10 anos)

As crianças principalmente, diferentemente dos adolescentes, reconhecem a escola como um local de aprendizado, mas isso não inclui apenas o aprendizado formal ou 
acadêmico. O aprender na voz das crianças também inclui uma dimensão mais lúdica, como aprender a desenhar, ou, junto dos amigos, a inventar uma brincadeira. Essa troca entre os pares também mostra que a criança/ adolescente consegue construir espaços de criação dentro do espaço escolar, de forma a reinventá-lo permanentemente. Outra coisa que essa fala mostra e que relembra as duas primeiras frases trazidas pela adolescente que acompanhamos, é que a escola é um espaço sim de "rasteira", tanto de regras quanto de transgressões às regras. Desse modo, parece haver sempre uma ambiguidade na relação com a escola, mas isso não necessariamente anula o prazer e a brincadeira. Observamos isso no caso de um menino de 5 anos que sempre furava a fila na hora do almoço e que, na aula e educação física, a professora tinha que chamar várias vezes a atenção dele pois sempre desobedecia às regras do jogo. Entretanto, esse mesmo menino, em entrevista com uma das pesquisadoras, diversas vezes fez, espontaneamente, menção à escola e aos aprendizados que tem tido lá.

Independente de ser falada por uma criança ou por um adolescente, a escola aparece sendo um lugar que tenta sempre ensinar a ter e a obedecer às regras. Não estamos aqui questionando a importância de se obedecer a regras, pois indiscutivelmente, em qualquer convivência social existem regras. Porém, as falas das crianças e dos adolescentes nos levam a refletir sobre o fato de que a escola muitas vezes se engessa em um excesso de regras que não se consegue cumprir nem serem justificadas para as crianças.

A partir das falas, percebe-se uma tensão instalada na escola. Nem sempre a escola é tão divertida assim, nem faz tanto sentido para os seus alunos, mas, apesar de muitas vezes reinar a arbitrariedade das regras e normas, isto não impede que as crianças e adolescentes criem espaços para emergirem enquanto sujeitos singulares no seu processo de escolarização.

Também se pode observar diferenças entre as crianças e os adolescentes, no que diz respeito ao seu discurso, pois falam de forma diferente sobre a escola. As crianças descreveram a escola utilizando um recurso mais lúdico. Elas desenharam, ou encenaram o seu cotidiano na escola, de modo que nota-se uma descrição da sua escola a partir de suas vivências, ou seja, as crianças "contam a escola". Já os adolescentes quando interrogados sobre o que eles achavam das suas escolas, responderam de forma mais direta, possuindo toda uma análise que atravessa as suas opiniões, muitas vezes críticas e irônicas, que nos mostram nitidamente como eles vêem a escola.

Independente da forma como se fala sobre a escola, as crianças e os adolescentes conseguem mostrar a ambiguidade da escola: apesar de ter regras, considerar mais o aprendizado formal e ser geograficamente fechada, também traz a possibilidade de aberturas que favorecem à criação e à construção de saberes singulares. Ou seja, pode-se talvez dizer, inspirados nas crianças e nos adolescentes, que a escola é um lugar "legalmente chato". Existe no espaço escolar, uma ambiguidade que lhe é constitutiva.
Porém, pensar nessa ambiguidade não é uma tarefa fácil. Tenta-se muitas vezes ignorá-la, de forma que isso acaba ficando sem espaço para emergir dentro da escola, e assim não pode ser trabalhado e elaborado, o que representa uma grande perda para que as crianças entendam esse embate do que é viver em sociedade, algo estrutural e produtivo. Assim, o mal-estar na civilização apontado por Freud deixa de ser produtivo e propulsor para ser reduzido apenas a queixas e angústias recorrentes.

\section{Considerações Finais: uma Escola Viva?}

Partirmos da existência de algumas teorias na psicologia e na educação que falam sobre a infância como apenas um período de transição a ser superado, e que durante este período caberia ao adulto conduzir este "ser" para um caminho marcado e invariável. Nessa perspectiva, a escola se constituiria como o local para que essa passagem até a idade adulta ocorra. Trata-se então de um "não importa o que a escola pode proporcionar no presente, mas sim o que ela poderá proporcionar em termos futuros" (Souza, 1996, p. 147). Porém, a partir dessa visão, sobraria para a criança apenas ocupar o lugar de um "não saber", cabendo-lhe apenas receber de forma submissa o conhecimento que lhe é oferecido. $\mathrm{E}$, quando isso não acontece, o recurso à medicalização tem sido cada vez mais utilizado para que a criança se adapte ao que lhe é exigido pela escola (Chistofaria \& cols., 2015; Merletti, 2012).

Essa visão está muitas vezes tão enraizada e naturalizada, que é comum ter-se dificuldade em pensar criticamente qual seria o papel social que a escola está exercendo e de que forma isso é feito. A escola hoje se sustenta e é sustentada pela lógica da eficácia e da técnica, em consonância com o discurso neoliberal que impera. Não havendo muito espaço para a criança como sujeito, a instituição muitas vezes tenta excluir as marcas de sua singularidade e de seu desejo. Nesse sentido, notamos no discurso dos educadores uma grande tendência em exigir o inatingível das crianças, centrando seu olhar muitas vezes exclusivamente nos aspectos cognitivos e em comportamento padronizado, o que deixa de fora a criança viva e singular. Foi com a finalidade de tentar entender melhor esse papel, e levantar reflexões sobre as dificuldades encontradas no ambiente escolar, que nos dedicamos a investigar o que dizem as crianças e os adolescentes sobre a escola.Consideramos que tais falas nos permitiram pensar sobre as exigências e ideais sociais colocados hoje na escola, pois "a palavra é a revelação dos valores fundamentais de uma dada sociedade e o modo como estes valores se explicitam e se confrontam" (Souza, 1996, p. 139).

Como vimos, com alguma frequência, as escolas têm seu funcionamento pautado na "sociedade da técnica", onde se espera que tudo deve funcionar extremamente bem. Ao contrário desse olhar, sabemos, desde Freud (1930/1980b), que na vida social, e, logo na escola, isto é algo impossível, 
pois a educação jamais chegará a uma finalização suficiente e definitiva. Por isso, acreditamos ser de grande importância que os educadores consigam entender que o mal-estar que emerge nas crianças e nos adolescestes, assim como nos próprios educadores, diz respeito ao embate inerente que existe entre a educação civilizatória e as pulsões, logo é algo inerente à cultura, e não apenas um "problema" individualizado de cada um. Enfim, dar a palavra às crianças e adolescentes que frequentam as escolas é também oferecer-lhes a possibilidade de expressar o mal-estar inerente a todo convívio social e assim, quem sabe, encontrar outros destinos para ele.

Para que haja uma escola viva, é preciso modificar a visão que temos do espaço escolar, a fim de incluir a dimensão sempre imprevisível, singular e inacabada que se encontra ao final da trajetória escolar, não como fracasso, mas sim como uma questão constitutiva da liberdade humana. Educar, requer uma relação entre o educador e o educado, porém muitas vezes isso é esquecido: Como observou Cifali (2009) aqueles que querem forjar um "outro" à sua medida, de acordo com um plano estabelecido e finalidades colocadas para o seu bem, percebem um dia que esse outro frustra seu plano, transforma-o e ressurge lá, onde não haviam previsto. Assim, pensar uma escola viva é pensar e aceitar que o encontro entre os alunos e os educadores será sempre imprevisível e se dará nas relações, sendo então necessária uma abertura para que o saber se construa no seu dia-a-dia, e de forma participativa, pois assim se perceberá a criança como sujeito, e não mais como um objeto de medidas a serem impostas. Pensar em uma educação que circula por todos que estão incluídos nesse ato de educar, é pensar em incluir a criança, ouvindo sua voz "não como uma infelicidade, mas como constitutivo de nossa relação com o outro-sujeito" (Cifali,2009, p.14).

A escola que constrói uma relação estritamente técnica e instrumental com o conhecimento leva as crianças/adolescentes a terem uma experiência escolar muito esvaziada de significados. Isso pode levar a um grande risco de que os alunos percam a oportunidade de encontrar na escola a chance de criar uma relação autêntica e criativa com o conhecimento.

\section{Referências}

Ariès, P. (1981). História social da criança e da família. Rio de Janeiro: LTC. Obra original publicada em 1973.

Audino, T.F. (2015). O imperativo da felicidade na contemporaneidade. (Dissertação de Mestrado). Programa de Pós-graduação em Teoria Psicanalítica, Universidade Federal do Rio de Janeiro, RJ.

Calastre, G. (1991). A criança no adulto. In: Miller, J. (Org.), A criança no discurso analítico (pp. 130-145). Rio de Janeiro: Jorge Zahar.

Carneiro, C.; Coutinho, L.G. (2014). Psicanálise e Educação, por um encontro possível. In: Coutinho, L.G.; Lehmann, L. (Orgs.),
Psicologia e Educação: Interfaces (pp. 33-48). Niterói, EDUFF.

Castro, L.R. (2008). Conhecer, transformar (-se) e aprender: pesquisando com crianças e jovens. In: Castro, L.R.; Besset, V.L. (Orgs), Pesquisa-Intervenção na Infância e Juventude (pp. 21-42). Rio de Janeiro: Nau.

Christofari, A.C.; Freitas, C.R.; Baptista, C.R. (2015). Medicalização dos Modos de Ser e de Aprender. Educação \& Realidade, 40(4), 1079-1102.

Cifali, M. (2009). Ofício "impossível"? Uma piada inesgotável. Educação em Revista, 25(1), 149-162.

Ferrari, I. (2008)Aignorância fecunda inerente à pesquisa-intervenção. In: Castro, L.R.; Besset, V.L. (Orgs), Pesquisa-Intervenção na Infância e Juventude (pp. 87-93). Rio de Janeiro: Nau.

Freud, S. (1980a). O ego e o id. IN: Freud, S., Obras Completas de Sigmund Freud (Vol. 19, pp. 23-83). Rio de Janeiro, RJ: Imago. (Trabalho original publicado em 1923).

Freud, S. (1980b). O mal-estar na Civilização. In: Freud, S., Obras Completas de Sigmund Freud (Vol. 21, pp. 81-178). Rio de Janeiro, RJ: Imago. (Trabalho original publicado em 1930).

Freud, S. (1980c). Análise terminável e interminável. In: Freud, S. Obras Completas de Sigmund Freud (Vol. 23, pp. 237-287). Rio de Janeiro, RJ: Imago. (Trabalho original publicado em 1937).

Kupfer, M.C. (1995). Freud e a Educação: o mestre do impossível. São Paulo: Scipione.

Luckesi, C.C. (2003). Avaliação da aprendizagem escolar: estudos e proposições (15a. ed.). São Paulo: Cortez.

Melman, C. (1994) Sobre a educação das crianças. In: Jerusalinsky, A. (Org.), Educa-se uma criança? (pp. 31-40) Porto Alegre: Ares e Ofícios.

Merletti, C.K.I. (2012). Hiperatividade, comportamento opositor e déficit de atenção: mal-estar da criança ou mal-estar do adulto ao infantil. $9^{\circ}$ Colóquio Internacional do LEPSI e $4^{\text {a }}$ RUEPSY: Retratos do mal-estar contemporâneo na educação, São Paulo, SP.

Rhoden, S.(2012) A pesquisa com crianças: a criança como sujeito de pesquisa. Revista Seminário Nacional de Arte e Educação, (23), 1-8.

Saviani, D. (2005). As Concepções Pedagógicas na História da Educação Brasileira. (Texto elaborado no âmbito do projeto de pesquisa "O espaço acadêmico da pedagogia no Brasil", financiado pelo CNPq, para o "projeto 20 anos do Histedbr"). Campinas: Projeto "20 anos do HISTEDBR".

Souza, S.J.(1996). Ressignificando a psicologia do desenvolvimento: uma contribuição crítica à pesquisa da infância. In: Kramer, S.; 
Leite, M.I. (Orgs.), Infância: Fios e Desafios da Pesquisa (pp. 3956). Campinas: Papirus.

Vasconcellos, C.S. (1992). Metodologia Dialética em Sala de Aula. Revista de Educação AEC, (83), 28-55.
Ventura, M.M. (2007). O estudo de caso como modalidade de pesquisa. Revista da SOCERJ, 20(5) 383-386

Yin, R.K. (2005). Estudo de caso: planejamento e métodos tradicionais ( $3^{\mathrm{a}}$ ed.). Porto Alegre: Bookman.

Recebido em: 23/01/2017

Aprovado em: 05/12/2017

Financiamentos: Cnpq (PIBIC), Faperj (Bolsas de Iniciação Científica), Proex/Uff (bolsa de extensão).

A pesquisa em questão teve a autorização do Comitê de Ética (número do parecer: 789.946) e da CRE (Coordenadoria Regional de Educação), que nos possibilitou a entrada nas escolas municipais, onde algumas das crianças/adolescentes estavam estudando durante o período de sua participação da pesquisa.

\section{Sobre as autoras}

Luciana Gageiro Coutinho (lugageiro@uol.com.br.)

Professora Adjunta da Faculdade de Educação da Universidade Federal Fluminense (UFF); Doutora em Psicologia pela Puc-Rio, psicóloga, psicanalista. Rio de Janeiro- RJ. https://orcid.org/0000-0001-9887

Cristiana Carneiro (cristianacarneiro13@gmail.com)

Professora Adjunta da Faculdade de Educação da Universidade Federal do Rio de Janeiro (UFRJ); Doutora em Psicologia pela UFRJ, psicóloga, psicanalista. Rio de Janeiro- RJ. https://orcid.org/0000-0002-4042-1155

Larissa Magalhães Salgueiro (larissamagalhaes_7@hotmail.com)

Psicóloga, bolsista de iniciação científica e de extensão 2013/ 2014 no projeto Infância, adolescência e mal-estar na escolarização: estudos de casos em psicanálise e educação (UFRJ). Rio de Janeiro - RJ. https://orcid.org/0000-0002-4153

(cc) $\mathbf{E Y}$

License information: This is an open-access article distributed under the terms of the License (type CC-BY), which permits unrestricted use, distribution and reproduction in any medium, provided the original article is properly cited. 
